\title{
Imaginario de nación en estudiantes universitarios de la ciudad de San José de Cúcuta
}

Héctor Fabián Parra Cabrera ${ }^{1}$, Claudia Elizabeth Toloza ${ }^{2}$, Mawency Vergel Ortega ${ }^{3}$.

Hace muchos siglos Salomón dijo: "Tal como es el hombre en su pensamiento, así es él".

"En el espacio euclideano de la historia, el camino más recto entre dos puntos es una línea recta, la del Progreso y la Democracia. Pero eso solo es válido para el espacio lineal de la Ilustración. En nuestro espacio no euclideano de finales de siglo, una curvatura maléfica desvía invenciblemente todas las trayectorias" Anónimo

\section{Resumen}

La nación constituye un punto de referencia del proceso modernizador y de integración en el contexto mundial, tanto, que desde diferentes áreas se han producido diversas y disimiles representaciones simbólicas y discursivas. Unas que la consideran sinónimo de progreso y otras, fuente de enajenación. La investigación tiene como objetivo, conocer el imaginario de nación que construyen jóvenes de la universidad Francisco de Paula Santander, sus representaciones, y en sus discursos detectar en qué medida éstos corresponden a la cultura a la cual pertenecen. Los resultados no dan cuenta total sobre un fenómeno sociocultural tan complejo; indagan e inician una revisión de lo que la nación ha representado para los estudiantes, a partir de sus creencias, costumbres y narraciones. El enfoque metodológico es cualitativo, la técnica de recolección de información es entrevista a profundidad aplicada a estudiantes de diferentes programas académicos de la Universidad Francisco de Paula Santander.

Palabras claves: Nación, imaginario, Colombia, topología, red.

\section{Abstract}

The nation is a benchmark of the process of modernization and integration into the global context, therefore, that from the literature have been numerous and dissimilar discursive and symbolic representations. Some who consider it synonymous with progress and other source of alienation. The research aims, the imaginary nation know that young that study in Francisco de Paula Santander, their representations, and in his speeches to detect the extent they relate to the culture to which they belong. Undoubtedly, it is not intended to account for a total complex sociocultural phenomenon, is expected to investigate and initiate a review of what the nation has meant to students based on their beliefs, customs and stories. The methodological approach is qualitative, the data collection technique is applied to in-depth interview a sample of students from different academic programs at the Universidad Francisco de Paula Santander.

Key words: Nation, imaginary, Colombia, topology, network.

\footnotetext{
${ }^{1}$ Abogado. Universidad Externado de Colombia, Especialista en Derecho Público. Universidad Externado de Colombia, Especialista en Derecho Electoral. Universidad del Rosario, Msc Derecho Público. Universidad Carlos III. España, Candidato a Doctor. Universidad de Granada. España.

${ }^{2}$ Psicóloga. Magister en Educación mención Gerencia Educativa. UPEL. Venezuela, Docente Universidad Francisco de Paula Santander, Estudiante Doctorado en Educación. UPEL. Venezuela.

${ }^{3}$ Licenciada en Matemáticas y Física. UFPS, Especialista en Estadística. UFPS, Especialista en Informática Educativa. UFPS, Magister en Educación mención Gerencia Educativa. UPEL. Venezuela, Docente Universidad Francisco de Paula Santander, estudiante Doctorado en Educación. UPEL. Venezuela.
} 


\section{Imaginario social, Imaginario urbano.}

Siguiendo el pensamiento de Castoriadis (1981) se puede decir que lo que mantiene unida a una sociedad, le otorga su singularidad propia, y la diferencia de otras sociedades y de la misma sociedad en diferentes épocas es, la compleja trama de significaciones imaginarias que orientan y dirigen la vida de la sociedad considerada y a los individuos concretos que corporalmente la constituyen (Castoriadis, 1981:68).

Este conjunto de significaciones compartidas, articulación que constituye el imaginario de nación en estudiantes de la Universidad, instituido, definen y estipulan lo que para dicho grupo será lo valorado o rechazado, lo normal, lo que es real y aquello que no lo es, lo que tiene sentido y lo que no lo tiene, lo cuestionable y lo imposible de pensarse. El concepto de Imaginario Social es entonces, utilizado con significados dispares, puede referirse a esquemas colectivos que intervienen, sin percibirse, en la construcción de la realidad social, los particulares marcos de referencia usados para la interpretación de las propias vivencias, los mecanismos del discurso que utiliza el poder para producir la realidad en su beneficio, los entramados culturales resultantes de la interacción entre discurso y práctica social, los sistemas ideológicos o simbólicos de la comunidad educativa. En matemáticas conjunto de esquemas organizadores condición de representabilidad de todo lo que una sociedad puede darse.

Por su parte, los imaginarios urbanos no se instalan en un pedazo de tierra, sino en lo que anima a una representación grupal de los estudiantes universitarios que constituyen familias y un subgrupo de la sociedad. La nación se constituye entonces en una red simbólica, donde el objeto nación se estructura de estímulos (perceptivo) que condiciona protocolos de uso operativo siendo la representación de un concepto o discurso social (cognitivo). Aflorando el objeto nación de las relaciones socioculturales, desde donde se hace un reconocimiento de los valores de la cultura, se gesta una cadena de relaciones que genera finalmente la identidad de un grupo y, funcionan así las relaciones sociales creando dos tipos de redes, la red simbólica y la red sígnica, en todo momento urbanizadas y la urbanización se da en redes. La red llega a considerarse un nuevo concepto contemporáneo sobre identidad.

Así, la teoría de los imaginarios urbanos busca captar y aislar para su estudio lo que llamamos "croquis urbanos", que no son otros que los mapas afectivos donde uno se encuentran con otros, ya sea porque se comparte un interés, un oficio o un tema. Y estos mapas no son físicos, son psicosociales (Figura 1), donde los croquis no se ven, se sienten. Si el mapa marca unas fronteras determinadas de propiedades políticas y geográficas, los croquis desmarcan los mapas y los hacen vivir su revés: no lo que se impone como frontera, sino lo que me impongo "como deseo. Los mapas son de las ciudades, los croquis pertenecen a los ciudadanos; entonces, un estudio de imaginarios fundados en las percepciones ciudadanas lo es de los croquis colectivos, donde en perspectiva se ubican los procesos de urbanización. El imaginario no es imagen, sino condición de posibilidad y existencia para que una imagen sea imagen de. Y el Todo es captado de manera derivada, como centro invisible de lo real-racional-simbólico que constituye toda sociedad.

Armando Silva, profesor de la Universidad Nacional, a través de los grafiti fue descubriendo discursos completos comprimidos en frases como "Abajo López y su mandato de hambre. MOIR", grafitti que adornó algunas murales en ciudades y pueblos colombianos durante el gobierno de Alfonso López Michelsen, resume la historia de varios años de lucha de un grupo político que mantiene vivas las esperanzas de un puñado de colombianos que quieren ver eliminada la injusticia social utilizando métodos pacíficos. Para Silva los grafiti son manifestaciones escritas en muros, paredes, volantes de imaginarios populares. Se observa en su trabajo el imaginario de algunos bogotanos sobre las calles y carreras de la ciudad que admite diversas formulaciones y elaboraciones donde todas las calles y carreras tienen nombres femeninos, pues "calles" y "carreras" son palabras de género femenino: "la décima", "la caracas", "la séptima", "la veintiséis", otras. Cada calle o carrera, las más importantes claro está, según los sucesos que ocurren en ella o que han ocurrido desatan en las mentes de algunos habitantes de 
Bogotá imágenes de contenido femenino que deleitan y hacen la vida menos desagradable. "La décima" con sus trancones interminables, sus aglomeraciones y sus raponeros, recuerda una "mala mujer"; "la veintiséis", ducto que conecta la ciudad con el aeropuerto, es la "viajera"; "la quince", eje principal de la zona rosa, es la "mujer encantadora", y otras. La pregunta ahora es que se podría pensar o imaginar ahora con el funcionamiento del transmilenio, macho que rueda por calles y carreras como "la ochenta" y "la caracas".

Figura 1. Mapa psicosocial. Tomado de http:/iscm.org

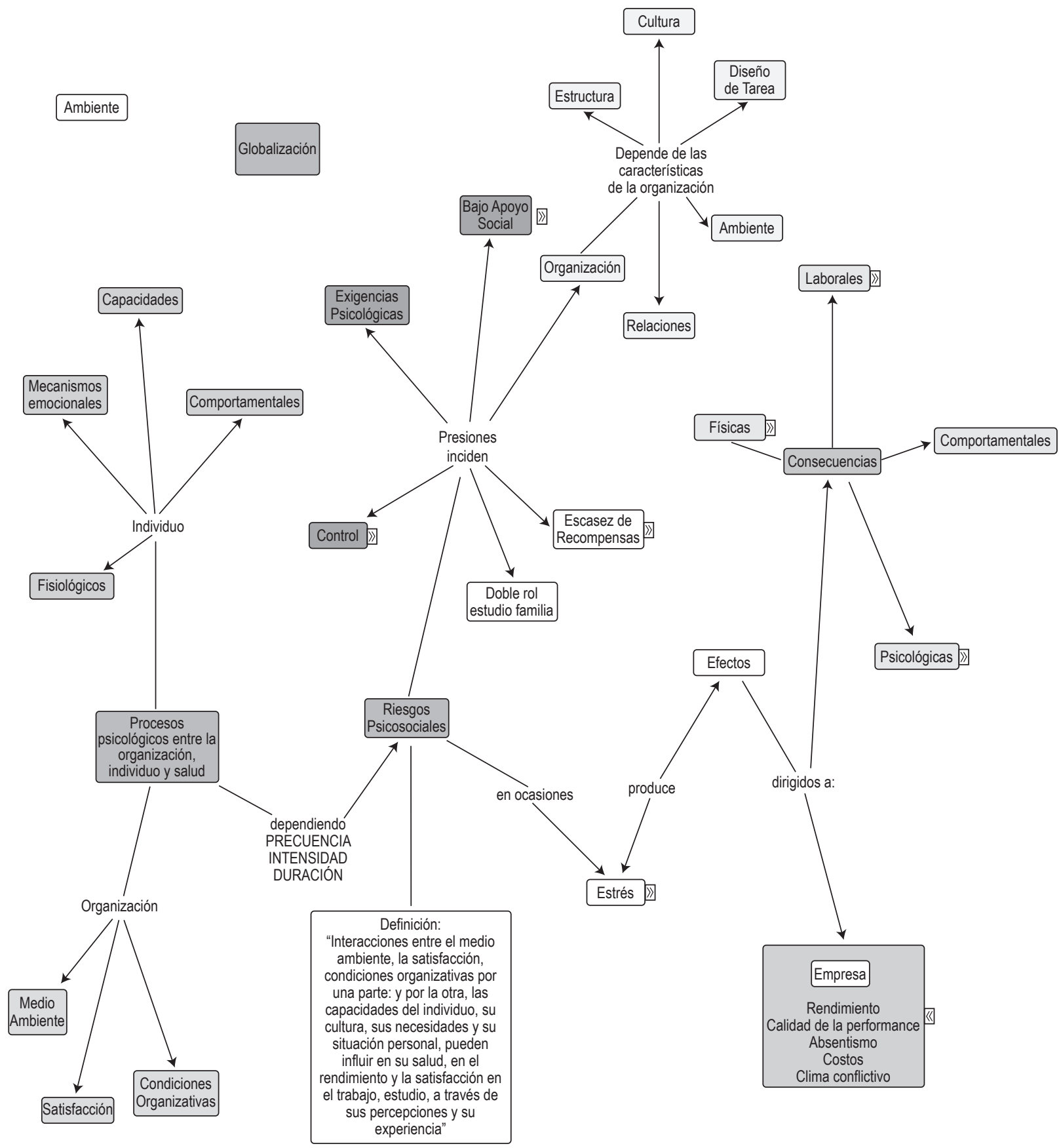


El lenguaje entonces representa siempre algo, que puede estar o no. Los jóvenes lo usan de manera simbólica, para el joven no se juega a ganar sino a jugar. Entones algo puede estar porque está en el lenguaje, por ejemplo cuando se pronuncia "Colombia" se dice la palabra Colombia, lo relevante es el lugar simbólico de Colombia como nación, aunque siempre queda un resto, no lo conocido por todos sino aquello que queda en el olvido, en el principio de las cosas que se hablan. Los niños se apasionan con las cosas, por ello pueden ver una películas muchas veces, lo que hace sentido es la búsqueda no el encuentro o si se encuentra finalmente encuentra lo que busca, porque siempre será lo que cada cual supone que es. Lo que se busca está en el lugar que poco se imagina.

El recorrido realizado conduce inevitablemente al ámbito educativo, en el cual la circulación de imaginarios de nación también es una realidad, por lo demás muy útil, cómo alcanzar autonomía académicamente, cómo evitar la manipulación mediante las modas? La respuesta a este interrogante no es inmediata pues las modas son muy útiles: por ejemplo, sirven de herramienta para la desobediencia civil; cuando aparece una nueva imposición esta se puede aniquilar convirtiéndola en una moda, en un cuento, en un chisme, en una historia, en una narración, en un imaginario. La autonomía académica, la identidad académica tan importante para el desarrollo de una actividad educativa de calidad, solo se puede alcanzar vinculándose a un grupo de investigación, participando en o manejando un proyecto de investigación dentro de ese grupo. Mediante su actividad investigativa, que debe ser permanente, cada joven estudiante universitario adquiere, como diría Kant, mayoría de edad, adquiere independencia y criterio para juzgar con relativa profundidad los sucesos nacionales que más le afectan, y sobre todo para distinguir las teorías de los imaginarios. Por eso es tan importante conocer los imaginarios y muy especialmente para saber trabajar con ambos en las instituciones educativas, para saber competir académicamente con ellos o cuando corresponda, saber cooperar con ellos.

\section{Pensamiento topológico}

Cuando se trata de pensar un sistema filosófico o un conjunto de categorías metafísicas, no se parte de la remisión a una presencia plena, o a principios a priori, ni se busca llegar a una fundamentación definitiva. Por el contrario, surge la deconstrucción y se trata de evidenciar la contingencia radical de todo principio, señalando, al mismo tiempo, que el principio, el "lugar cualquiera" que se erige en cada caso como origen, "está superdeterminado por estructuras históricas, políticas, filosóficas, fantasmales que, por principio, no se pueden nunca explicar ni controlar completamente" (Bennington y Derrida, 1994: 44). Debido a su compromiso radical con la contingencia, el proceder filosófico de Derrida lo concibe como pensamiento estratégico revela presupuestos metafísicos y sus límites donde se podría decir se encuentra un pensamiento in situ o topológico, que en cada caso traza un mapa transitorio de relaciones conceptuales, configurando así el lugar mismo desde el cual se toma la palabra, signado por una contingencia radical, esto significa que las estructuras que lo "superdeterminan" por principio no se pueden explicar ni controlar plenamente. En este sentido, el lugar en el que se sitúa la reflexión es siempre nebuloso, un plexo de apertura más que un punto fijo de referencia. La determinación de este "lugar" es estratégica, en tanto funciona como un escalón provisional para el análisis de los conceptos y valores metafísicos que delimitan un sistema.

Esta concepción del lugar, supone factores desde "históricos" hasta "fantasmales", pretende superar la comprensión tradicional que lo liga a un espacio físico, a límites geográficos. Espacio y tiempo siempre son concebidos relacionalmente por un contraste mutuo, de donde se sigue que no parece posible determinar el espacio sin recurrir a categorías temporales y viceversa; en este casolugar, tensión indisoluble. De esta manera, el ejercicio cartográfico, la definición de un lugar o territorio de la palabra, demanda un análisis deconstructivo, una revisión constante y un esfuerzo repetido para revelar nuevas determinaciones provisionales, consecuencias necesarias de lo que significa la "differánce". Por este motivo se considera con frecuencia que la deconstrucción funciona como 
una coartada para eludir todo compromiso teórico y político, como una simple estrategia para evadir la responsabilidad política de una toma de posición (Derrida y Stiegler, 1998: 18). "El pensamiento de la différance es entonces un pensamiento de la urgencia, de lo que no puedo eludir ni apropiar porque es otro. El acontecimiento, la singularidad del acontecimiento: ésa es la cosa de la différance" (Derrida y Stiegler, 1998: 23). Esto es algo claramente ejemplificado por la situación misma que supone la realización de la entrevista, coyuntura desde la cual está pensando la cuestión de la "actualidad". Derrida señala que entre más neutral y transparente se presenta la técnica, más cuidado debe tenerse con respecto a sus implicaciones políticas y sociales.

Hoy en día más que nunca, pensar en el tiempo (sobre todo cuando al hacerlo se corre el riesgo o la suerte de la palabra pública) consiste en tomar nota, para ponerlo en práctica, del hecho de que el tiempo de esa misma palabra se produce artificialmente. Es un artefacto. En su mismo acontecer, el tiempo de ese gesto público es calculado, forzado, "formateado", "inicializado" por un dispositivo mediático. El espacio público de nuestro presente está siendo producido, lo que significa que sólo puede ser captado en diferido, desde las variables tecnológicas que vehiculan su actualización. En este sentido, pensar el presente supone de alguna manera constituirlo técnicamente, pues no es posible una relación no-mediática, pura, con lo real (cf. Stiegler, 2002: 35). De este modo, el carácter topológico de la deconstrucción que coincide con un pensar desde la inmanencia de los medios, implica ahora la inmersión en procesos tecnológicos de producción. De acuerdo con esto, la configuración de un lugar es siempre derivada de dispositivos tecnológicos, en sus consonancias e interferencias rítmicas.

En efecto, si lo que acontece históricamente, lo que pasa al primer plano de la actualidad, se deriva de sus respectivas mediaciones, podría decirse que lo representativo de la cultura y la historia de una nación es el resultado de un conjunto de dispositivos técnicos, ordenados en relación con una perspectiva privilegiada en cada caso, y no de principios trascendentales como los que suelen invocarse en los discursos demagógicos. En este contexto, para Derrida la responsabilidad política, un compromiso con la justicia, surge de la constatación del carácter parcial de toda actualización histórica, pues sólo así se puede reconocer el sacrificio u olvido de perspectivas o testimonios que también son significativos por ser radicalmente "otros" (cf. Derrida y Stiegler, 1998: 24-25). Desde las nuevas tecnologías de la imagen, aunque parece que ellas proporcionan cada vez más opciones para la intervención directa de los usuarios, también pueden generar nuevas formas de manipulación, nuevos nacionalismos o dogmatismos con consecuencias políticas indeseables (cf. Derrida y Stiegler, 1998: 76-77).

En este orden de ideas pensar deconstructivamente la nación desde un contexto con jóvenes universitarios implica en cierto sentido producir desde su situación o territorio específico, siempre en función de una revisión crítica de sus presupuestos discursivos, su perspectiva hegemónica y sus "olvidos".

\section{Nación}

Una de las tendencias encontradas en las definiciones de nación se relaciona con la categoría identidad, según afirma Johan Gottfried Von Herder 1744-1803) filósofo alemán, la personalidad dejaría de ser un asunto individual y se tornaría propiedad de un grupo étnico, asumiendo así el colectivismo. La nación según Herder no puede ser alterada, cuestionada o transformada porque se arriesgaría la identidad

El concepto de Nación surge en la época de la Revolución Francesa, se consolidó en el siglo XIX en Europa y América y en el siglo XX en Asia, África y Oceanía. El concepto de Nación hace referencia al sentimiento de pertenencia a una comunidad, por razones históricas, étnicas, lingüísticas o religiosas. Nación se relaciona con nacer. En algunos textos se observa que esta concepción ha conducido a nacionalismos extremos que excluyen durante muchos años a quienes tienen otro origen étnico y exacerban con consecuencias drásticas, las diferencias, los conflictos interraciales y económicos. Sus partes constitutivas son entonces el idioma, la historia común, el territorio habitado o abarcado, la memoria y la conciencia nacional o de identidad 
que se concretan en la disposición por los mismos propósitos y valores. Se encuentra la nación, país o habitantes de un territorio, pueblo, patria; nación política, en el ámbito político-jurídico, como sujeto político en el que reside el concepto de soberanía de un Estado; y nación cultural, concepto socio-ideológico, comunidad humana con características culturales comunes, a las que dota de un sentido político.

En torno al individuo y su conceptualización, todo sujeto o individuo forma parte de una cultura heredada, recoge fragmentos de las culturas que le parece bueno recoger. Se llega a plantear, respecto al concepto de nación, la dicotomía entre sociedad mecánica y orgánica, resaltando la homogeneidad cultural y la diversidad, asimilando la nación a una sociedad orgánica, la cual, pese a la diversidad existente, debe ser homogénea en algún sentido, puesto que las actividades son diversificadas pero todas están codificadas por escrito en una lengua ampliamente inteligible. También, se llega a evocar también la dicotomía entre comunidad y sociedad para explicar la naturaleza de la nación, como lo hace Morin cuando sostiene que: "La nación es una sociedad en sus relaciones de interés, de competiciones, de rivalidades, ambiciones, conflictos sociales y políticos. Pero es igualmente una comunidad identitaria, una comunidad de actitudes y una comunidad de reacciones frente al extranjero y sobre todo al enemigo." (Morin, 1993: 454)

La masificación cultural es un proceso apenas formal y oficial y no cotidiano mientras no coexista con un fluido intercambio comercial. En Colombia, por ejemplo, los Radicales intentaron la unificación nacional a través de la educación general y laica para todos los colombianos, pero al mismo tiempo federalizaron el país en nueve Estados, cada uno de los cuales tenía una salida al río Magdalena, como vía expedita para conectarse a los mercados externos pero no se pensó nunca en establecer nexos comerciales con el resto de las regiones. De esta forma los intereses regionales que pugnaban por hacerse oír dieron al traste con el proyecto. Los regeneradores, en cambio, empezaron por tratar de unificar el país a través de caminos y ferrocarriles, moneda única y poder centralizado, y de más intercambios económicos internos, dejando la educación en manos de la
Iglesia y para elites, incorporando a la masa al proyecto nacional a través religiosos y arengas políticas y militares, y de instituciones nacionales como la iglesia, el ejército y la policía nacional. De otra parte se genera identidad cultural y la ideología, entendida sobre las maneras como la cultura transa información reflejando el modo social como viven y se relacionan las personas, y las condiciones particulares de existencia que justifican o rechazan; por lo tanto, el objeto es una ideología tridimensional que estructura una cultura material que es la materialización de las esperanzas de un grupo

Durante la independencia el clero no fue homogéneo, sacerdotes y obispos fueron constituyentes, participaban en política algunos con ideas liberales, la reforma del siglo XVI golpeó la iglesia en bienes y poder. En el siglo XIX existían luchas entre clero y España, por ello, a mediados de siglo forma con el partido conservador y los liberales buscan un estado laico. Delimitar un territorio, soberanía y geografía que tiende al particularismo en el siglo XIX eran cuestiones básicas y prioritarias, al no haber vías de comunicación, se ensayó la forma central y luego federal. Siendo la mejor época de la economía la del federalismo. El federalismo se mantiene durante tiempos, hubo constantes agitaciones, aptitudes fuertes, uniendo a la necesidad de un estado central produciendo la guerra de los mil días. Estado nación y conmemoraciones de la independencia desarrollan la historiografía y en los doscientos años el país ha avanzado mirado en perspectiva Colombia no ha tenido guerras internacionales, los caudillos militares no tuvieron preponderancia de otras partes y existieron dictaduras muy débiles, se crea una sociedad civil, inicialmente con bipartidos que dominó muchos años y hoy con múltiples partidos. Existen élites y sectores paupérrimos marginados que constituyen en la deuda social de Colombia.

Colombia enfrentó en los años 90 problemas como la injusticia conectada con el narcotráfico, lo cual hace necesario fortalecer el Estado, el M19 y grupos indígenas que hace que el gobierno realice inversión social duplicando el PIB, políticas neoliberales permiten que se incluya el Estado en el sector privado pero se dispara el gasto social, la educación se universalizó, aparece la ley 100 
aunque aún hoy existen cuotas de analfabetismo, no se ha podido desarrollar una cultura laica, científica, de la escritura en esta época.

El hombre vio la necesidad de la representación de materializar objetos, ritos, formas de ver su realidad a través del tiempo en monumentos, concentrado en valores históricos, políticos, posibilidad de producir y reconstruir formas de comprensión de la realidad de cada época, con una comprensión metafísica del mundo, de relatos locales, algunos vistos como esquemas de vida. En Colombia representan no solo la persona que está sino la intención política en la cual se decide colocar el monumento. Hoy en torno a este tema, lamentablemente se tecnifica lo material, creando un sistema de significados que no significan ni representan algo, de otra parte, se observa como las sociedades contemporáneas al romper su vínculo con la metafísica no valora las producciones materiales las miden por la producción y utilidad que tengan.

El siglo XX en Colombia es considerado como siglo del consumo masivo, los flujos mediáticos a los que está expuesto el individuo, masificación de hábitos de los individuos, la música, la radio, la televisión se constituyen en cursos formadores y deformadores de la cultura que configura conductas y prácticas sociales, configura el entorno social de los individuos, fruto de este constante flujo de imaginarios que se configuran a partir y alimentan de una mezcla hibridación cultural donde los lenguajes, hábitos, símbolos que se alimenta de estos canales de internación y se reconfiguran realidades sociales. Basura, escoria, términos que utilizan para describir la música de la época, rock, pop, rap, break dance, así mismo surgen lenguajes como el grafiti.

Así como se reseña en la Constitución Política de Colombia de 1991 "Colombia es un Estado social de derecho, organizado en forma de república unitaria, descentralizada, con autonomía de sus entidades territoriales, democrática, participativa y pluralista, fundada en el respeto de la dignidad humana, en el trabajo y la solidaridad de las personas que la integran y en la prevalencia del interés general". Donde el Estado debe entenderse como el agrupamiento social en un territorio determinado y reconocido, constituido bajo la legitimidad de un poder político público, que abarque normas respaldadas jurídicamente para mantener un orden social.

Colombia hoy, es considerada una sociedad dinámica donde hay cambios de diverso tipo. En los últimos cinco años en la década de América latina estos cambios son rápidos y se darán donde las políticas gubernamentales coadyuvarán a cumplir metas para tener un mejor país. Inversiones especiales en primera infancia, minería, salud, educción, derechos humanos, inversiones donde se encuentran inmersas familias dispuestas a superar crisis. Se ve a Colombia como una nación en crecimiento con propuestas académicas en el sector urbano y rural, construyendo películas completas registrando información para reconstruir la sociedad, donde cada región a través de locomotoras manifiestas en el Plan de Desarrollo nacional, se constituyen en polo de desarrollo importante. Como se manifiesta en el comercial Colombia es Pasión: "Colombia es un lugar que desafía todos los días la imaginación, un lugar con un mar de siete colores, donde los ángeles vienen de vacaciones, amurallada abierta al mundo, se siente cerca siempre de ti, un paraíso donde las ballenas vienen de vacaciones, con ciudades que crecen, que siempre está de moda, un país lleno de historia y cultura donde un día vienes y no piensas en volver a tu país de origen, con la gente que quieres tener cerca de ti, un lugar que cada día se esmera en sorprenderte de manera distinta, Colombia el riesgo es que te quieras quedar".

\section{Contexto universitario}

La Universidad Francisco de Paula Santander (UFPS) tiene como misión el ser "una institución pública de educación superior, orientada al mejoramiento continuo y la calidad en los procesos de docencia, investigación y extensión, cuyo propósito fundamental es la formación integral de profesionales, comprometidos con la solución de problemas del entorno, en busca del desarrollo sostenible de la región".

En el II semestre de 2010, la UFPS cuenta con 20561 estudiantes en 55 diferentes programas académicos ofertados por la institución. 519 estudiantes pertenecen a grupos étnicos, de los 
cuales, un $4.8 \%$ pertenecen a la etnia motilón Barí; 880 estudiantes manifiestan provenir de situación de desplazamiento, de éstos, 45.2\% provienen de situación de desplazamiento de otros departamentos, $34.3 \%$ provienen de otros municipios del Norte de Santander, el porcentaje restante proviene de sectores aledaños al Municipio de Cúcuta. Es importante resaltar que 41 de los estudiantes matriculados en programas de pregrado a distancia de la UFPS, son reclusos de cárceles de los Santanderes (48.8\% cárcel modelo de Cúcuta, $14.6 \%$ cárcel Buen Pastor, $36.6 \%$ cárcel Palogordo en Bucaramanga).

Teniendo en cuenta la distribución del origen geográfico de los estudiantes de pregrado, un 64.4\% es nacido en el Municipio de Cúcuta, 5.7\% en Municipios del área metropolitana, 10.86\% en Municipios del Norte de Santander, 15.4\% de Municipios de otros departamentos y un 1.4\% son extranjeros. El índice de absorción de estudiantes actualmente es del 64\% y, Según tipo de colegio del cual egresan, un $78.2 \%$ es egresado de instituciones de educación media de carácter oficial, y $21.7 \%$ de carácter privado. Teniendo en cuenta la edad un $48.5 \%$ ingresa a la educación superior con una edad entre 18 y 19 años, un 35.9 entre 16 y 17 años. En torno a estrato socioeconómico predomina el estrato uno y dos.

\section{Resultados}

Figura 2. Network View: Familias de Nación

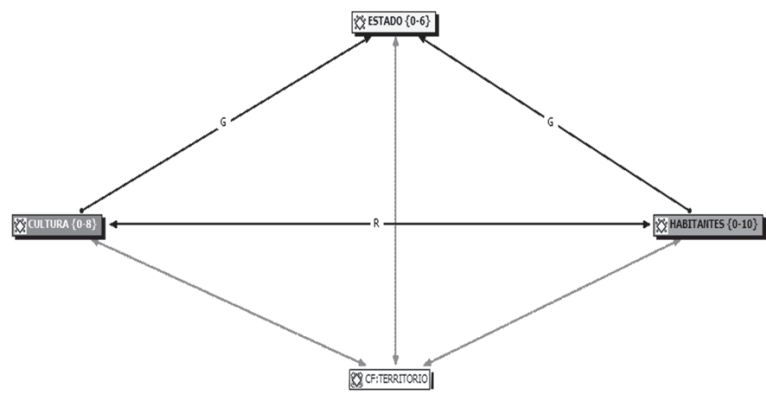

$\mathrm{Al}$ interpretar expresiones de los estudiantes, se manifiestan cuatro familias en torno a Colombia como nación, la primera familia relacionada con Colombia como Estado con elementos como población, derecho, reconocimiento donde se busca dar a entender que, en un mundo globalizado, el Estado que no sea reconocido por la comunidad internacional tiende a ser ilegítimo. La segunda Familia Cultura, la tercer familia Habitantes íntimamente relacionada con población, y como cuarta familia el territorio.

Figura 3. Network View: Grupo Estado

Code Families (1): CF:ESTADO

Codes (4):

Heroes $\{14-0\}$

Política $\{9-0\}$

Problemas $\{3-0\}$

Símbolos $\{11-0\}$

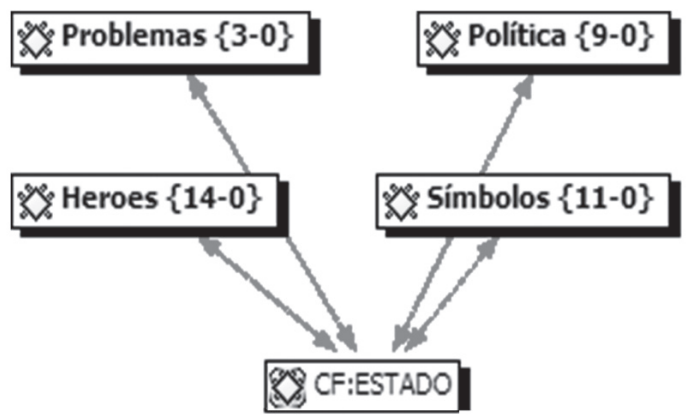

Los estudiantes de la Universidad Francisco de Paula Santander, diferencian términos nación de Estado, donde la nación es un grupo de habitantes que, en un mismo territorio y regidos por un mismo gobierno, forman un país, y esos habitantes se caracterizan por tener unas mismas costumbres y hábitos; y por su parte el Estado, es entendido como concepto político referido a una forma de organización social soberana de un territorio determinado, o conjunto de instituciones que poseen autoridad y poder para establecer las normas que regulan una sociedad, teniendo soberanía interna y externa sobre un territorio determinado.

Pero Colombia manifiesta, es un territorio en el cual conviven diferentes pueblos, razas, credos y lenguas; para ellos, la nación incluye el desarrollo de una cultura común y la realización personal de los habitantes dentro de una sociedad, mientras que el Estado lo enfocan hacia la definición de parámetros jurídicos que guían al país nacional. Al ser incluyentes la Familia Estado está relacionada de manera significativa con subgrupos como la política, problemas que aquejan a la sociedad y políticas y las leyes que surgen para proteger la sociedad, le relacionan con los héroes que surgen y con los símbolos que utiliza nuestro pueblo, 
nuestra gente, nuestras ciudades y el gobierno.

Figura 4. Network View: Grupo cultura

Network View: CULTURA

Created by: Super 2010-12-28T00:42:56

Nodes count: 7

Code Families (1):

CF:CULTURA

Codes (6):

Bailes $\{1-0\}$ Comida $\{1-0\}$ costumbres $\{5-0\}$ Personajes $\{6-0\}$ razas $\{3-0\}$

sonidos $\{2-0\}$

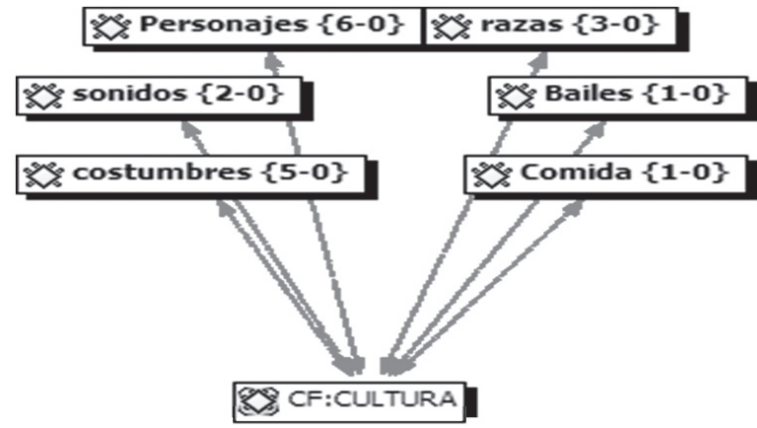

La cultura en los estudiantes de la Universidad Francisco de Paula Santander, se origina en el momento en que se relacionan variables como costumbres, personajes, razas, sonidos, bailes y comida típica. La colectividad toma un entorno natural y crea un entorno artificial. De las relaciones entre estas se originan la comunicación, las condiciones psicoafectivas, la pertenencia y todas las condiciones sociales producto de sus relaciones sintácticas. La cultura se constituye en un conjunto estructurado de maneras de pensar, sentir y obrar más o menos formalizadas, que aprendidas y compartidas por el conjunto de individuos de la universidad, sirven, de un modo sígnico y simbólico a la vez, para constituir a esas personas en una colectividad particular y distinta. Por ello se consolida como un sistema donde existen variables intervinientes como familia, imagen, medio, moda y pensamientos de amigos cercanos, entre otros.

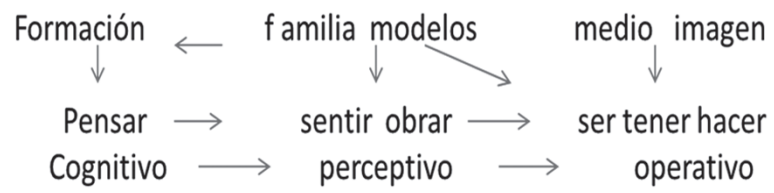

Como se observa en la Figura 5, la formación se relaciona directamente con el pensar y éste con el desarrollo cognitivo, se encuentra cercanía entre familia y modelos con el sentir de los estudiantes, su manera de percibir la cultura, el arte, la necesidad de conservar costumbres de sus ancestros y algo significativo de recuperar expresiones dichos de sus abuelos, chistes; u en otros casos no significativos en el entorno UFPS de cambiar o mantener nuevos estilos que les permite crear diferencia (emos, grupos estudiantiles). Esto, entonces los lleva a ser parte de un medio donde proyectan su imagen, y operan sus pensamientos sintiéndose todos parte de "una hermosa nación".

Figura 6. Network View: Grupos habitantes - territorio

Network View: TERRITORIO

Created by: Super 2010-12-28T00:45:44

Nodes count: 3

Codes (2):

Fauna $\{3-0\}$

Geografia $\{4-0\}$
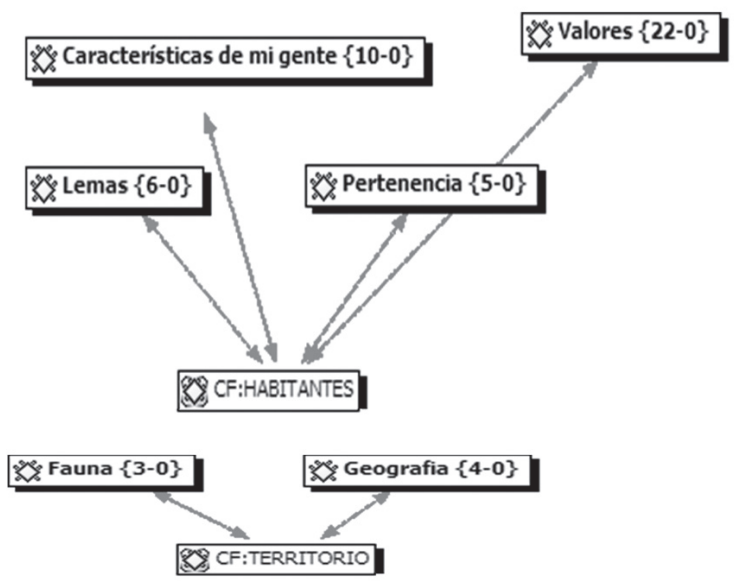

El grupo Territorio (Figura 6), en torno a la nación es relacionado por los estudiantes de la UFPS con la Fauna y geografía del país. Definido territorio como tierra, área definida (incluyendo tierras y aguas) a menudo considerada posesión de una persona, organización, institución, animal, estado o país subdividido. Al referirse a territorio, se observa una red sígnica, en la cual, los estudiantes cuentan con valores particulares de su microcontexto Universidad Francisco de Paula Santander, nueva red que les permite comunicarse, sentirse parte integral de un centro de educación, sintiendo que allí cuentan con otra familia estructurando un sistema de valores subjetivos (ideología, estética de la universidad) que los llevan a tener un alto 
sentido de pertenencia por su universidad. Se encuentra así, un alto porcentaje de los jóvenes que inician hablando de nación, de Colombia y culminan mencionando su Universidad, su infraestructura, sus alumnos, profesores, sus ritos, costumbres. Le mencionan como su segundo hogar, su historia tiene lugar entonces en este punto de la geografía. De esta fragmentación surge la necesidad de una red que no los deje separarse completamente y las mantenga en coherencia la red simbólica, constituye para la imagen colectiva la universidad un nuevo elemento dentro de la nación, un lugar en el territorio que les permite leer e interpretar una cultura creando su propia memoria cultural, se forja en un medio ideal para tridimensionalizar su información ideológica. De la memoria cultural y su residualidad en la sociedad se crean los referentes pragmáticos, que para efectos de la materialidad son recursos de expresión, lectura e interpretación tridimensional de mensajes culturales.

Por su parte el grupo habitantes transversal a todas las familias de nación, se relaciona con características, valores, pertenencia, lemas. Se ha creado en el colectivo de estudiantes un conjunto de caracteres que hacen que como individuos o grupo se sientan reconocidos sin posibilidad de confusión con otros. Resaltando una identidad fuerte hacia la universidad, la nación, su cultura. Los recursos materiales, como el objeto desde donde se puede autorreferenciar y reconocer no se desvanecen ni ocultan por el consumismo ni la funcionalidad, algunos grupos tratan de insertarse pero no lo han logrado y ha sido responsabilidad del objeto la representación de situaciones socioculturales.

En torno a la identidad, expresiones de estudiantes llaman la atención y hace entrever el sentimiento y aferro a su alma mater como parte de la nación Extiendo los brazos y puedo acariciar las delgadas paredes que delimitan las calles. Avanzo tímidamente, alguien habla al móvil, sigo caminando sigiloso, se escucha cantar; infinidad de colores y estímulos detienen mi mirada. Tropiezo con una mesa y una silla, naturaleza por doquier, objetos personales se entrevén través de las ventanas. En las oficinas de directivas, me invade la duda si estaré invadiendo la intimidad de alguien, si estaré traspasando la delgada línea entre público y privado que inunda el ambiente. $\mathrm{Y}$ al final de la intimidad del pasaje que conduce de la torre administrativa a las aulas de clase, ahí estaba la luz, el verde, libros, equipos, mis amigos, mi gente, la amplitud y el dominio sobre la universidad situada en la ciudad, un punto en el país, un inmenso sitio en nuestra mente. Y, "La sociedad se preocupa por saber que somos, mas no se preocupa por saber quiénes somos o que queremos ser. Nuestra Colombia es una tierra santa, una tierra de sentimiento y de parranda"

Figura 7. Códigos

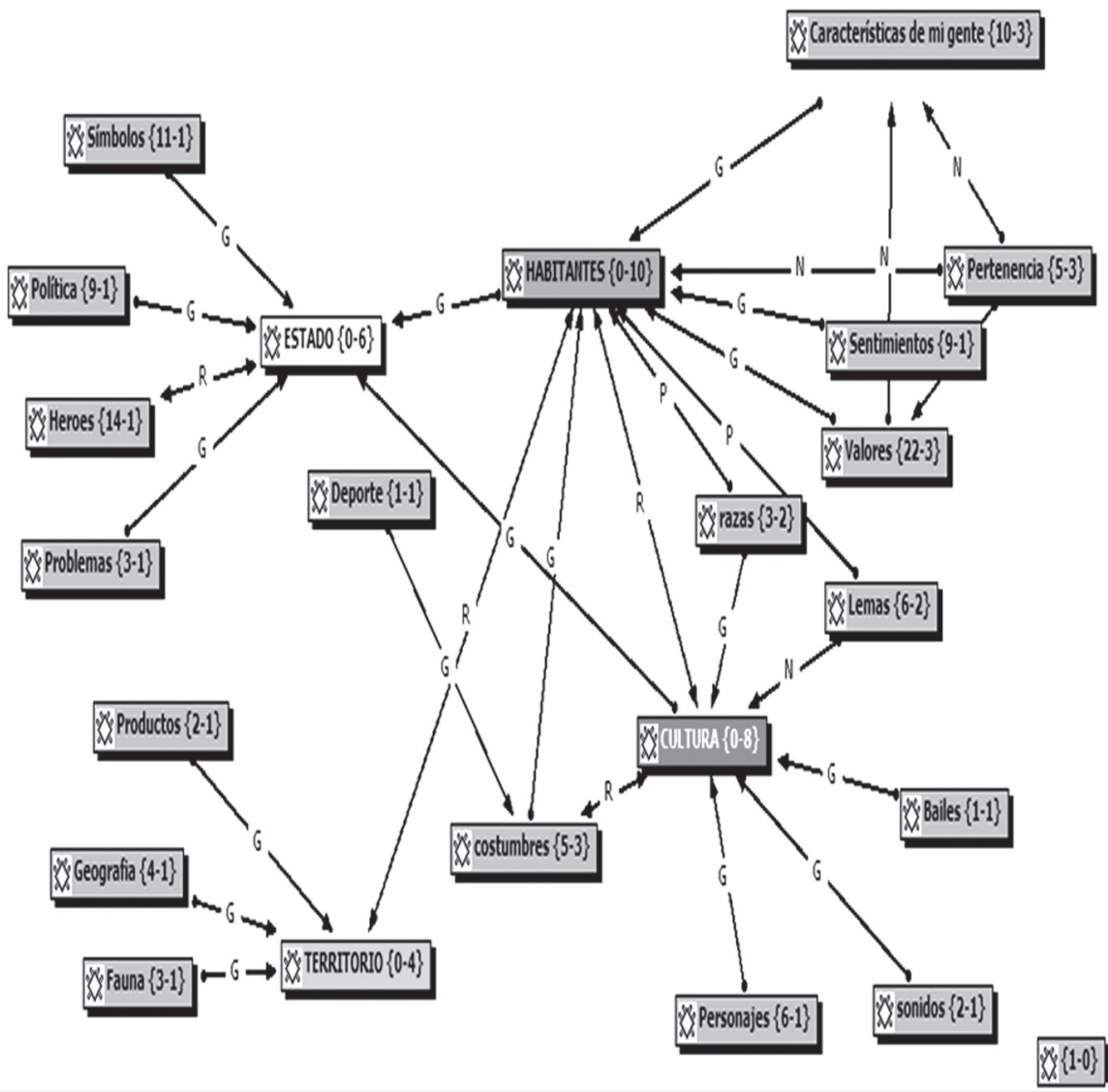




\section{Analisis entrevistas}

El análisis de las entrevistas (Figura 7) realizadas muestra un alto sentido de pertenencia hacia el país, se menciona de manera repetitiva la palabra orgullo, patria, y expresiones como mi país, nací aquí, entre otras muestran los valores que se sienten hacia la nación. La nación de acuerdo al análisis, está conformada por sus habitantes, por su cultura, el Estado y el Territorio. Todos estos conceptos (Familias) son las que le dan forma al imaginario de nación.

La nación la conforma entonces un grupo de habitantes con valores como pasión, responsabilidad, amor por la patria, con características como alegres, serviciales, hospitalarios, con sentimientos de amor, orgullo por el país, por sus símbolos como la bandera, el himno, el escudo, un grupo multicultural con costumbres y hábitos que le dan vida a una Cultura rica en bailes, folclor, música, comida típica, y personajes ubicados todos en un territorio rico en productos como el café, con sitios turísticos y zonas geográficas montañosas atractivas y una fauna representativa en zonas como Cartagena y el Amazonas, regidos por un mismo gobierno, forman un país, un estado con parámetros jurídicos, un país político, democrático con organización social soberana de un territorio que incluye instituciones tales como las fuerzas armadas, la administración pública la policía, asumiendo pues el Estado (diferente a nación) las funciones de defensa, gobernación, justicia y seguridad.

La observación de jóvenes en la Universidad Francisco de Paula Santander, permite ver cómo el flujo mediático del país y la inserción de personas de otras culturas del ámbito mundial en Colombia, ha dado lugar a la formación de tribus urbanas a partir de interiorización de conductas, hábitos, signos, símbolos que configura nuevos grupos sociales frutos de la mezcla entre la mediología y condiciones sociales específicas de nuestra época.

Para todas las personas que conviven en un país en el cual hay obras, estas obras le cambian su imaginario, su perspectiva, aquellas imágenes cambian significativamente porque para ellas no es lo mismo recorrer una avenida que tenía un carril, no es igual pensar en ir de la mano; este escenario cambia en una avenida sin pavimento por una autopista, o en las nuevas existentes en el país, con una cantidad de carriles, con movimiento de personas diferentes, expresiones como "todo cambia, cambia la persona, la movilidad", manifiestan cambios en el pensamiento, en la representación, los medios, la cultura, en el imaginario colectivo. En torno a las calles, en algunas ciudades de Colombia se vive caos,manifiestan otros estudiantes, desembotellando la acumulación de personas con calles insuficientes para flujo vehicular, reconociendo la necesidad de un país imaginado con ciudades imaginadas ideales donde exista compromiso de cada habitante cuidando la ciudad, su infraestructura, con cultura ciudadana donde esa visión que se tiene de la ciudad cambie, todo nace de cada individuo, el principal componente, el ciudadano. La cultura juega un papel importante y a partir de ello se crean nuevas cosas nuevas, el compartir, el no hacer daño, el cuidar, de la convivencia, de la vida y saber que eres parte del cambio, "se busca una sociedad más fraterna, porque el hombre nació para ser sociable, donde todo comienza desde la familia".

De otra parte, se encuentran individuos que consideran debe primar el medio ambiente y la sostenibilidad quienes en sus relatos tienen expresiones como "Como salvar un país que se vuelve más ladrillo, más concreto", existe resistencia porque esto juega con lo ambientalista. Por tanto, se resalta la necesidad del deber existir compensación entre arquitectónico y el medio ambiente, donde la sociedad debe continuar con un planeta que se debe oxigenar. De igual manera se encuentran jóvenes de acuerdo con la construcción, la industrialización, la mejora en obras, mejora en espacios, modernidad y cambio de ciudades pequeñas en mega-ciudades.

Así mismo, los estudiantes universitarios, manifiestan que en Colombia actualmente se puede manifestar públicamente lo que se piensa, pero piensan que solo los medios pueden expresar cierto sentir, restringiendo a la población al derecho de la libre expresión, en este contexto los jóvenes plantean un nuevo imaginario con un centro foco de opinión, lugar donde todos puedan expresarse, opinar y hacer críticas libremente, apropiarse, dando paso a la alimentación, 
reflexión, discusión y debate. La idea es convertir las calles en una obra de arte participativo colectivo. Interviniendo generando dos dinámicas generando dos dinámicas distintas, una diurna y una nocturna en torno a generación de una construcción pública y colectiva de opinión. Para la generación de opinión consideran intervenir un paradero llenando de poster pequeños en blanco y colgando lápices, motivando la participación de ciudadanos por medio de pancartas con el tema de opinión. Intervenciones en sitios importantes del centro de ciudad. Paraderos de uso obligatorio y espacios públicos de uso colectivo, interviniendo paradero, parques, una vez a la semana con una temática diferente para activar la afluencia poster con imágenes de Colombia, para activación de vida nocturna, es factible dicen usar muros de poco uso, en los cuales se expongan videos de arte que expongan trabajos, ideas en una temática semanal propuesta, áreas de proyección que puedan cambiarse semanalmente. Gestionando el uso de estos espacios dentro y fuera de la universidad.

Para la arquitectura proponen crear fachadas galerías, donde toda la comunidad y grupos de interés internos y externos: jóvenes, niños, ancianos, sin distinción de creencias ni estrato, pueda expresarse, pintar, dibujar, escribir. La imagen será el medio que genere la opinión. El eje temático semanal busca dar dinamismo a actividades y generar discusión a aspectos de la vida diaria en sociedad en la nación, desde lo trascendental hasta lo más efímero y vanal. Creación de páginas web donde se suban registros fotográficos y fílmicos, donde exista mayor accesibilidad a todo el público, se adquieran más seguidores. Internet medio de mayor escala para exponer la realidad colombiana en el exterior. Nuevas ideas, libre expresión permite crear imaginarios colectivos que permiten forjar una mejor idea de lo que la nación representa, una mayor afluencia de visitantes que generen mayor colorido, la ciudad como forjador de cambios, contribuyendo a mejorar estética, creando espacios lúdicos que brinde esparcimiento y cultura.

\section{Conclusiones}

La conclusión principal de esta pequeña exploración conlleva a constituir un nuevo ámbito de investigación en torno a los imaginarios en las instituciones. Una institución educativa debe cumplir la función fundamental de contribuir al fortalecimiento y desarrollo de la cultura nacional, para ello, es indispensable develar aquellos obstáculos que, según Bachelard, son más fáciles de manejar: los del espíritu, los que produce el cerebro en su indeclinable tarea de generar bienestar. Si el individuo no se siente bien, construye sus propias razones para eludir las incomodidades; resulta más importante problematizar acerca de estas razones, que pueden estar ocultas o subconscientes, que hostigar a los jóvenes y comunidad con multitud de innovaciones. Las innovaciones son cruciales pero, se estrellan con imaginarios que obstaculizan su apropiación, incluso, mal llevadas, pueden dar origen a nuevos imaginarios que refuerzan la tradición; y sobre todo, cuando son impuestas la única respuesta posible es la resistencia civil, particularmente con un imaginario.

En torno a la nación, existe en los jóvenes de la Universidad Francisco de Paula Santander, un alto sentido de pertenencia hacia Colombia, una imagen positivista de nación, entendida como un conjunto de habitantes de diferentes razas y culturas, que habitan en un mismo territorio y regidos por un mismo gobierno, forman un país, y esos habitantes se caracterizan por tener unas mismas costumbres y hábitos. Una nación con bellezas naturales, que se encuentra en crecimiento, donde se respetan ideologías, credos, una nación que vivió y vive la violencia pero con un gobierno que genera acciones para cambiarla, una nación con gente amable, con una historia, con símbolos presentes en el ámbito internacional y una cultura que consideran debe conservarse y registrarse a través de diferentes medios.

La relación con el pasado y el futuro de la nación y el imaginario de los jóvenes de la universidad Francisco de Paula Santander, parece intrínsecamente ligada a la memoria, los relatos de sus familias, y a la "teletecnología" de la escritura alfabética. De ahí provienen en buena medida sus formas de reflexividad, de comprensión del mundo. Lo que ocurre hoy en día es una experiencia del límite histórico en su origen y su fin, en cierto modo en su origen y terminación, por tanto, el límite de la escritura fonética la referencia a lo espectral, la comprensión de que 
todo acontecimiento es ambiguo lleva a pensar que la herencia, lo heredado, exige de cada individuo una apropiación, y esta apropiación depende de los registros que permiten los medios que tenemos a disposición.

\section{Bibliografía}

Bachelard Gaston. La formación del espíritu científico. Siglo XXI Editores, México, 1978.

Bachelard Gaston. El aire y los sueños. Fondo de Cultura Económica, Breviarios, 5ae ed., México, 1989.

Bachelard. Gaston. La tierra y los ensueños de la voluntad. Fondo de Cultura Económica, Primera reimpresión, México, 1996.

Barlow Horace. Imagen y conocimiento. Drakontos, Barcelona, 1990.

Bennington, Geoffrey y Jacques Derrida. Jacques Derrida. Trad. María Luisa Rodríguez Tapia. Madrid: Cátedra. 1994

Bishop Alan. Enculturación matemática. Paidos, Barcelona, 1999.

Castoriadis Cornelius. Los dominios del hombre. Gedisa, Barcelona, 1986.

Derrida, Jacques. De la gramatología. Trad. Oscar del Barco y Conrado Ceretti. México: Siglo XXI. 1986

Grijelmo Alex. La seducción de las palabras. Taurus, Madrid, 2000.

Kline Morris. El pensamiento matemático de la antigüedad a nuestros días. Alianza Universidad, Madrid, 1992.

Moscovici Serge. Psicología Social I. Paidos, Barcelona, 1985.

Niño Murcia Soledad y otros. Territorios del miedo en Santafé de Bogotá: imaginarios de sus ciudadanos. Google.com/territorios del miedo en Santafé de Bogotá: imaginarios.

Silva Armando. Imaginarios urbanos en América Latina. Los imaginarios y la cultura popular. Editorial Presencia, Bogotá, 1993
Stiegler, Bernard. La técnica y el tiempo. Vol. 1. Trad. Beatriz Morales Bastos. Hondarribia: Hiru. 2002 